\title{
PVC/MMT nanocomposites
}

\section{DSC with stochastic temperature modulation study at glass transition region}

\author{
Joanna Pagacz $\cdot$ Krzysztof Pielichowski
}

Received: 31 January 2012/ Accepted: 8 May 2012/Published online: 26 June 2012

(c) The Author(s) 2012. This article is published with open access at Springerlink.com

\begin{abstract}
Poly(vinyl chloride) (PVC) nanocomposites with sodium montmorillonite (Na-MMT) and organically modified MMT (O-MMT) have been prepared by melt processing using mixing and extrusion techniques. The differential scanning calorimetry (DSC) with stochastic temperature modulation $\left(\mathrm{TOPEM}^{\mathrm{TM}}\right.$ ) results show that the glass transition temperature $\left(T_{\mathrm{g}}\right)$ of $\mathrm{PVC}$ is slightly higher than $T_{\mathrm{g}}$ of PVC/Na-MMT and PVC/O-MMT which would indicate that MMT plays a role of an internal plasticizer that increases the distance between the PVC macrochains. The DSC TOPEM non-reversing heat flow profiles show enthalpy relaxation effects, and the lowest value has been found for pristine PVC-the presence of MMT (both Na+ and ammonium salt modified) may generate a certain orientation level of PVC macrochains during the extrusion process. Specific heat vs temperature dependencies at different frequencies revealed that the best fit to the single profile was found for PVC/Na-MMT nanocomposite, and this observation may be related to internal stability of the composite material as confirmed by analysis of the change in the specific heat $\left(\Delta c_{\mathrm{p}}\right)$.
\end{abstract}

Keywords PVC nanocomposites - DSC - TOPEM · Glass transition

\section{Introduction}

Poly(vinyl chloride) (PVC) nanocomposites with layered silicates, especially montmorillonite, have gained increased

J. Pagacz $(\varangle) \cdot$ K. Pielichowski

Department of Chemistry and Technology of Polymers,

Cracow University of Technology, ul. Warszawska 24,

31-155 Kraków, Poland

e-mail: jpagacz@chemia.pk.edu.pl attention in recent years due to reinforcement effects induced by inorganic filler. Improved thermal resistance, enhanced stiffness and barrier properties, as well as flame retardation have been reported [1-6].

Besides, the processing conditions for low-filled polymeric nanocomposites are similar to these of pristine resin and typical problems of microcomposites' processing, such as changes in melt viscosity or surface roughness of molded parts, do not occur. Owing to nanometric dimensions of montmorillonite particles (close to the molecular dimensions), large interphase area is achieved at low filler content [7]. Furthermore, when montmorillonite is properly modified and dispersed in the polymer matrix, effective interactions arise between organic and inorganic phases of composite material that can cause synergistic effects $[8,9]$.

The enhancements of the thermal properties of PVC/MMT nanomaterials were described in the literature [10-12], and it is generally accepted that the lamellar crystal structure of MMT platelets with high aspect ratio play a decisive role in restricting the molecular dynamics of the macromolecular matrix. However, plasticized PVC shows unusual elasticity due to three-dimensional network structure that consists of microdomains of around $100 \AA$, primary crystallites (platelet or flat needle-like lamellar structures), and secondary fringed micellar crystallites [13, 14]. It is still unclear how this complex hierarchical-type PVC morphology is affected by nanostructured MMT platelets under heating at glass transition region. More information can be obtained on those effects if temperature-modulated DSC is applied. In this technique, the heating rate changes continuously, and thus it is possible to separate the sensible $\left(\Phi_{\text {sens }}\right)$ and latent $\left(\Phi_{\text {latent }}\right)$ heat flow components. Different temperature programs (e.g., sinusoidal or saw-tooth) allow determination of the heat capacity changes and analysis of relaxation processes by measuring the frequency 
dependence of thermal processes. Useful combination of heat components separation and multi-frequency modulations is offered by a new technique-TOPEM ${ }^{\mathrm{TM}}$ DSC. In this method, a stochastic temperature modulation makes possible the analysis of dynamic behavior of material during one single measurement-without a need to make "blank" measurements. This analysis is based on the correlation between the heating rate and heat flow. It leads to the quasi-static heat capacity $c_{\mathrm{p}, 0}$, the frequency-dependent complex heat capacity, $c_{\mathrm{p}}^{*}(\omega)$ and the non-reversing heat flow $\Phi_{\text {non-rev }}$. The second part of the heat flow-reversing component is calculated from the quasi-static heat capacity. Using sufficiently low heating rates $\left(0.01-2 \mathrm{~K} \mathrm{~min}^{-1}\right)$ and small temperature perturbation $\delta T_{0}$ (a parameter to fulfill linearity conditions) $1 \mathrm{mK}-0.5 \mathrm{~K}$, it is possible to obtain reversing and non-reversing heat flows identical as a sensible and latent heat flow component [15-17].

Hence, the aim of this article is to analyze the influence of MMT (both non-modified and organically-treated) on the glass transition region of industrial-mode formulated $\mathrm{PVC}$, including relaxation effects.

\section{Experimental}

Materials

Suspension poly(vinyl chloride) $(K=67$, Polanvil S-67 HBD) was supplied by Zaklady Azotowe ANWIL S.A. (Poland); the commercial nanoclays: sodium montmorillonite (NaMMT) and MMT modified by benzyldimethyloctadecylammonium chloride (Nanofil ${ }^{\circledR}$ SE3010) were provided by Süd Chemie (Germany). Other additives were as follows: plasticizer-dioctyl phthalate (DOP_Zaklady Azotowe Kedzierzyn S.A., Poland); stabilizer-calcium stearate (Boryszew ERG S.A., Poland); chlorinated flame retardant-chloroparaffin (Konimpex, Poland); flame retardant-aluminum hydroxide (ATH, Alfrimal 103 from Alpha Calcit Füllstoff GmbH, Germany); and compatibilizer/plasticizer-epoxidized soybean oil (Ergoplast ES from Boryszew ERG S.A., Poland). All materials were dried before use.

Preparation of PVC/MMT nanocomposites

PVC/MMT nanocomposites were obtained by a two-step method-at the first stage, a masterbatch was prepared by mixing suspension PVC with MMT and other additives in a high-speed mixer. The second step was processing of the homogeneous mixture in a double-screw micro-extruder (HAAKE MiniLab II). The operating temperature region of
Table 1 Composition of PVC/MMT nanocomposites

\begin{tabular}{lr}
\hline Composition & wt\% \\
\hline PVC & 100 \\
DOP & 40 \\
Calcium stearate & 2 \\
Chloroparaffine & 5 \\
ATH & 25 \\
Epoxidized soybean oil & 3 \\
MMT & 3 \\
\hline
\end{tabular}

the micro-extruder was maintained (after a set of optimizing experiments) at ca. $140{ }^{\circ} \mathrm{C}$. The operating screw's speed was maintained at $70 \mathrm{rpm}$, and the melt material has been circulated in the extruder's backflow channel. The composition of PVC/MMT nanocomposites is specified in Table 1.

\section{Method}

DSC measurements with stochastic temperature modulation have been performed using a METTLER TOLEDO $823^{\mathrm{e}}$ DSC. The following parameters were chosen: the underlying heating rate $-2 \mathrm{~K} \mathrm{~min}^{-1}$, the amplitude of the temperature pulse $- \pm 0.25 \mathrm{~K}$, the switching time range (which limits the duration of the pulses) - min. $15 \mathrm{~s}$ and max. $30 \mathrm{~s}$, and the sample weight—ca. $17 \mathrm{mg}$.

\section{Results and discussion}

TOPEM DSC profiles of plasticized PVC, PVC/Na-MMT, and PVC/O-MMT nanocomposites are shown in Fig. 1.

Glass transition temperature $\left(T_{\mathrm{g}}\right)$ of $\mathrm{PVC}\left(57.4^{\circ} \mathrm{C}\right)$ is slightly higher than $T_{\mathrm{g}}$ of PVC/Na-MMT $\left(54.7^{\circ} \mathrm{C}\right)$ and PVC/O-MMT $\left(52.4{ }^{\circ} \mathrm{C}\right)$. These observations would indicate that the mobility of polymer chains is not restricted in the confined environment of layered silicate platelets-on the contrary, MMT acts as an internal plasticizer which increases the distance between the macrochains. In consequence, the degree of interactions between polymer chains becomes lower and $T_{\mathrm{g}}$ decreases. In general, the glass transition of polymer nanocomposites is profoundly influenced by the relative strength of the chain-particle interactions and the morphology, particularly the particle dispersion and the interparticle spacing [18]. Sufficiently, strong particle-chain enthalpic interactions lead to permanent attachment of chain segments to the nanoparticles. Under these conditions, polymer nanocomposites have been shown to exhibit two glass-transition temperatures: one associated with polymer chains far from the nanoparticles and the second associated 
Fig. 1 DSC TOPEM profiles of a $\mathrm{PVC}$, b $\mathrm{PVC} / \mathrm{Na}-\mathrm{MMT}$, and c $\mathrm{PVC} / \mathrm{O}-\mathrm{MMT}$
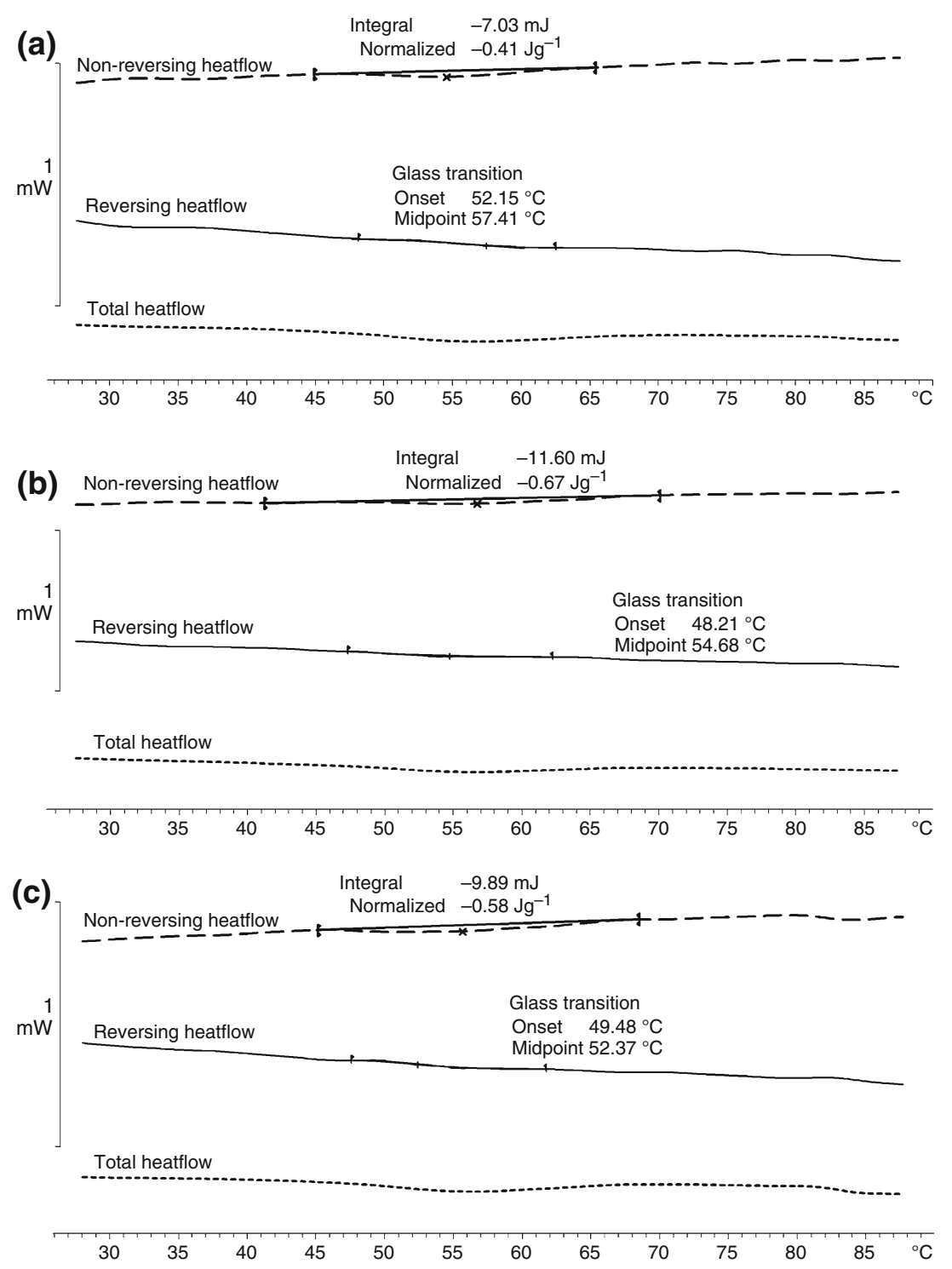

with chains in the vicinity of the nanoparticles $[19,20]$. In our system under investigation, a single $T_{\mathrm{g}}$ was observed indicating that PVC-MMT enthalpic interactions are rather weak. Besides, the existence of single glass transition evidences that the plasticizer (DOP) is able to penetrate not only the intermicrodomain region of amorphous PVC but also microdomains themselves [14, 21].

It seems that in the highly plasticized systems in which the presence of a plasticizer eases the motion of macrochains, the extent of this effect is larger than effect of constraints induced by nanoadditive-MMT. Although there are numerous evidences for constraining the polymer chain motions on the nanometer scale by layered silicates ("nanoconfinement effects") which may occur both in the intragallery space and at or near the MMT surface [22], it is still a subject of debate in regard to plasticized blends which effect prevails. Since the enhanced interchain interactions correlate with increases in the activation energy of the glass transition, it would be advisable to perform relaxation kinetic analysis for PVC/MMT systems - such studies are in progress.

The non-reversing heat flow curves made it possible to determine the enthalpy relaxation effects, and the lowest value has been found for PVC $\left(0.41 \mathrm{~J} \mathrm{~g}^{-1}\right)$ in comparison to PVC/Na-MMT $\left(0.68 \mathrm{~J} \mathrm{~g}^{-1}\right)$ and PVC/O-MMT $\left(0.58 \mathrm{~J} \mathrm{~g}^{-1}\right)$. The presence of MMT (both $\mathrm{Na}+$ and ammonium salt modified) may generate a certain orientation level of PVC macrochains during the extrusion process. Then the cooling rate is too fast to allow macromolecules to rearrange in a thermodynamical equilibrium configuration, and they remain in an 'out of equilibrium' glassy state with internal stresses unrelaxed.

Specific heat vs temperature dependencies for measurements of pristine PVC, PVC/Na-MMT, and PVC/O-MMT 
Fig. 2 Specific heat vs temperature plots at different frequencies for a PVC, b PVC/ $\mathrm{Na}-\mathrm{MMT}$ and $\mathbf{c} \mathrm{PVC} / \mathrm{O}-\mathrm{MMT}$
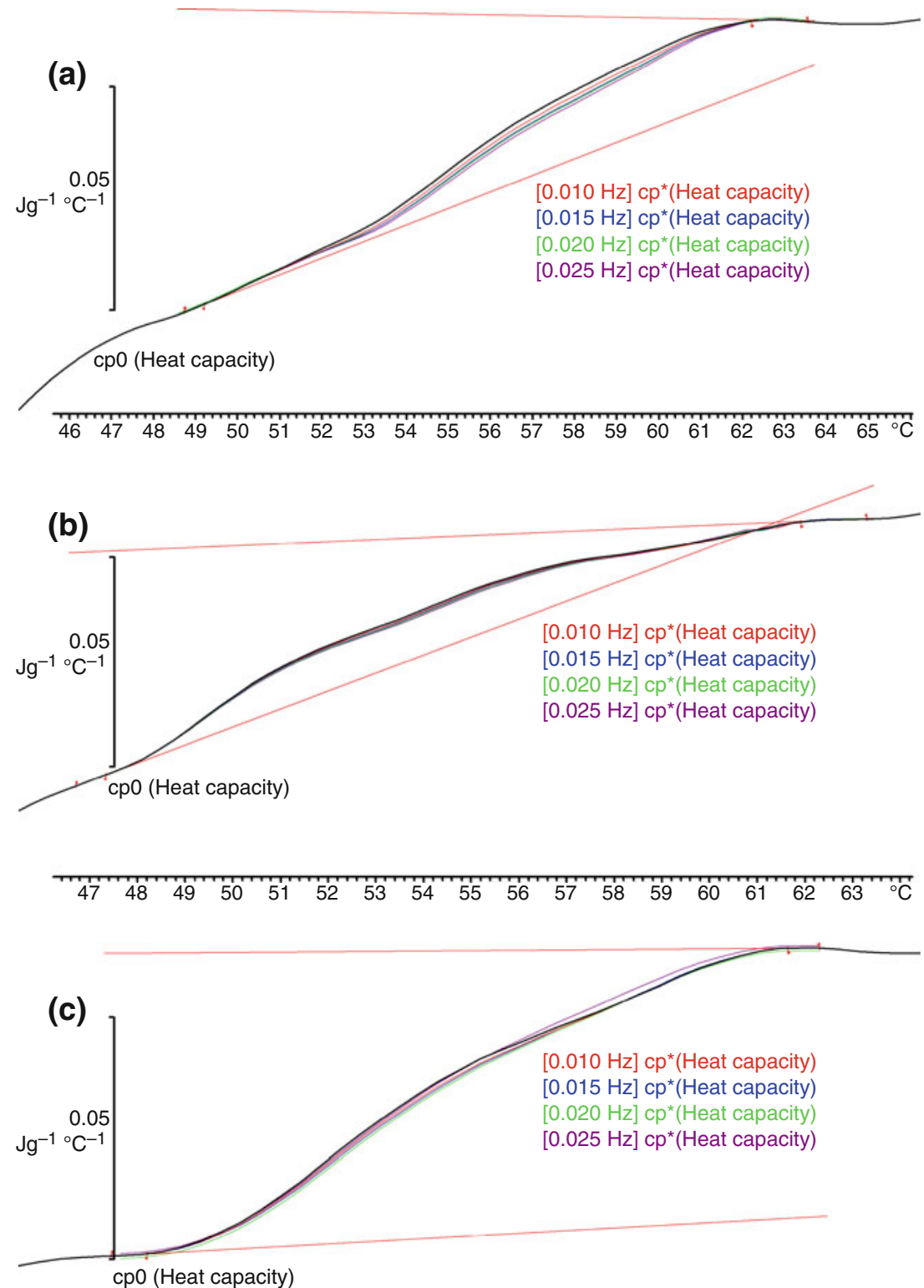

nanocomposites at different frequencies are displayed in Fig. 2.

Interestingly, the best fit to the single profile was found for $\mathrm{PVC} / \mathrm{Na}-\mathrm{MMT}$ nanocomposite, and this observation may be related to internal stability of the composite material-the less prone the specific heat is to changes in temperature frequencies in the dynamic TOPEM DSC experiment, the more robust the structure of the tested material is. This effect was confirmed by analysis of the change in the specific heat $\left(\Delta c_{\mathrm{p}}\right)$ with the lowest value for PVC/Na-MMT blend. Since the size of the step change in the specific heat at the glass transition temperature is a measure of the increase in number of rotational modes of the main chain segments which become active at the transition, the lowest value for PVC/Na-MMT nanocomposite indicates its relative stability. The PVC/Na-MMT nanocomposite does not contain organic modifier of MMT (benzyldimethyloctadecylammonium chloride) which may either undergo degradation during processing or disadvantageously interact with the components of industrial PVC formulation.

\section{Conclusions}

DSC with stochastic temperature modulation proved to be an efficient method to distinguish reversing and nonreversing heat flow components in the glass transition region for PVC/MMT nanocomposites. Based on TOPEM 
DSC data, it has been found that the glass transition temperature $\left(T_{\mathrm{g}}\right)$ of $\mathrm{PVC}\left(57.4^{\circ} \mathrm{C}\right)$ is slightly higher than $T_{\mathrm{g}}$ of PVC/Na-MMT $\left(54.7^{\circ} \mathrm{C}\right)$ and PVC/O-MMT $\left(52.4{ }^{\circ} \mathrm{C}\right)$. It proves that MMT is not restricting the mobility of polymer chains through formation of a confined environment, but it acting as an internal plasticizer which increases the distance between the macrochains. It causes that the interactions between polymer chains become weaker and $T_{\mathrm{g}}$ value decreases. A single $T_{\mathrm{g}}$ was observed indicating that PVCMMT enthalpic interactions are rather weak. Besides, the existence of single glass transition evidences that the plasticizer (DOP) is able to penetrate not only the intermicrodomain region of amorphous PVC but also microdomains themselves. Non-reversing DSC TOPEM heat flow curves show enthalpy relaxation effects, and the lowest value has been found for PVC in comparison to PVC/Na-MMT and PVC/O-MMT. The possible explanation could be that the presence of MMT (both $\mathrm{Na}+$ and ammonium salt modified) may generate a certain orientation level of PVC macrochains during the extrusion process, and some internal stresses remain unrelaxed. Analysis of the specific heat vs temperature dependencies at different frequencies revealed that the best fit to the single profile was found for PVC/Na-MMT nanocomposite, and this observation may be related to internal stability of the composite material as confirmed by analysis of the change in the specific heat $\left(\Delta c_{\mathrm{p}}\right)$.

Acknowledgements The authors are grateful to Mr. Beat Flachs-

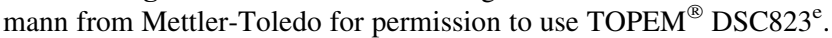

Open Access This article is distributed under the terms of the Creative Commons Attribution License which permits any use, distribution, and reproduction in any medium, provided the original author(s) and the source are credited.

\section{References}

1. Zheng X, Gilbert M. An investigation into the thermal stability of PVC/montmorillonite composites. J Vinyl Addit Technol. 2011:17:77-84

2. Dimitry OIH, Sayed WM, Mazroua AM, Saad ALG. Poly(vinyl chloride)/nanoclay nanocomposites-electrical and mechanical properties. Polimery. 2009;54(1):8-14.

3. Rodolfo A Jr, Innocentini Mei LH. Poly(vinyl chloride)/metallic oxides/organically modified montmorillonite nanocomposites: fire and smoke behavior. J Appl Polym Sci. 2010;116:946-58.

4. Madaleno L, Schjřrdt-Thomsen J, Cruz Pinto J. Morphology, thermal and mechanical properties of PVC/MMT nanocomposites prepared by solution blending and solution blending + melt compounding. Compos Sci Technol. 2010;70:804-14.
5. Sterky K, Hjertberg T, Jacobsen H. Effect of montmorillonite treatment on the thermal stability of poly(vinyl chloride) nanocomposites. Polym Degrad Stab. 2009;94:1564-70.

6. Peprnicek T, Duchet J, Kovarova L, Malac J, Gerard JF, Simonik J. Poly(vinyl chloride)/clay nanocomposites: X-ray diffraction, thermal and rheological behavior. Polym Degrad Stab. 2006; 91:1855-60.

7. Kiersnowski A, Trelińska-Wlaźlak M, Gazińska M, Pigłowski J. $\mathrm{X}$-ray scattering and calorimetric studies of organoclays obtained by ion-exchange. Polimery. 2011;56(9):671-5.

8. Leszczyńska A, Njuguna J, Pielichowski K, Banerjee JR. Polymer/montmorillonite nanocomposites with improved thermal properties Part I. Factors influencing thermal stability and mechanisms of thermal stability improvement. Thermochim Acta. 2007;453:75-96.

9. Leszczyńska A, Njuguna J, Pielichowski K, Banerjee JR. Polymer/montmorillonite nanocomposites with improved thermal properties Part II. Thermal stability of montmorillonite nanocomposites based on different polymeric matrixes. Thermochim Acta. 2007;454:1-22.

10. Gong F, Feng M, Zhao C, Zhang S, Yang M. Thermal properties of poly(vinyl chloride)/montmorillonite nanocomposites. Polym Degrad Stab. 2004;84:289-94.

11. Mingliang GE, Demin J. Influence of organoclay prepared by solid state method on the morphology and properties of polyvinyl chloride/organoclay nanocomposites. J Elastomers Plast. 2008;40: 223-35.

12. Xu WB, Zhou ZF, Ge ML. Polyvinyl chloride/montmorillonite nanocomposites. Glass transition temperature and mechanical properties. J Therm Anal Calorim. 2004;78(1):91-9.

13. Wilkes CE, Summers JW, Daniels CA. PVC handbook. 1st ed. Munich: Carl Hanser Verlag; 2005.

14. Gomez Ribelles JL, Diaz-Calleja R, Ferguson R, Cowie JMG. Glass transition and physical ageing in plasticized poly(vinyl chloride). Polymer. 1987;28:2262-6.

15. Schawe JEK, Heter T, Hertz C, Alig I, Lellinger D. Stochastic temperature modulation: a new technique in temperature-modulated DSC. Thermochim Acta. 2006;446:147-55.

16. Fraga I, Montserrat S, Hutchinson JM. TOPEM, a new temperature modulated DSC technique. Application to the glass transition of polymers. J Therm Anal Calorim. 2007;87(1):119-24.

17. Fraga I, Montserrat S, Hutchinson JM. Vitrification and devitrification during the non-isothermal cure of a thermoset. Theoretical model and comparison with calorimetric experiments. Macromol Chem Phys. 2010;211:57-65.

18. Pryamitsyn V, Ganesan V. Origins of linear viscoelastic behavior of polymer-nanoparticle composites. Macromolecules. 2006;39: 844-56.

19. Tsagaropoulos G, Eisenburg A. Direct observation of two glass transitions in silica-filled polymers. Implications to the morphology of random ionomers. Macromolecules. 1995;28:396-8.

20. Oh H, Green PF. Polymer chain dynamics and glass transition in athermal polymer/nanoparticle mixtures. Nat Mater. 2009;8: $139-43$.

21. López J, Balart R, Jiménez A. Influence of crystallinity in the curing mechanism of PVC plastisols. J Appl Polym Sci. 2004;91: 538-44.

22. Chen K, Harris K, Vyazovkin S. Tacticity as a factor contributing to the thermal stability of polystyrene. Macromol Chem Phys. 2007;208:2525-32. 